\title{
EFFICIENT APPROACH FOR DESIGNING A PROTOCOL FOR IMPROVING THE CAPACITY OF ADHOC NETWORK
}

\author{
Suresh Kurumbanshi ${ }^{1}$ and Dr. Shubhangi Rathkanthiwar ${ }^{2}$ \\ ${ }^{1}$ Department of Electronics \& Telecommunication Engineering, Y.C.C.E, Nagpur, \\ Maharashtra-India \\ ${ }^{2}$ Department of Electronics Engineering, Y.C.C.E, Nagpur, Maharashtra-India
}

\begin{abstract}
In Adhoc Network, prime issues which affects the deployment, design and performance of an Adhoc Wireless System are Routing, MAC Scheme, TCP, Multicasting, Energy management, Pricing Scheme \& self-organization, Security \& Deployment consideration. Routing protocols are designed in such a way that it should have improvement of throughput and minimum loss of packets. Another aspect is efficient management of energy and the requirement of protracted connectivity of the network. The routing algorithm designed for this network should monitor the energy of the node and route the packet accordingly. Adhoc Network in general has many limitations such as bandwidth, memory and computational power. In Adhoc Network there are frequent path break due to mobility. Also time synchronization is difficult \& consumes more Bandwidth. Bandwidth reservations requires complex Medium Access Control protocol. In this field the work of quantitative and qualitative metrics analysis has been done. The analysis of protocol performance for improving the capacity of adhoc network using probabilistic approaches of the network is yet to be proposed. Our probabilistic approach will cover analysis of various computational parameters for different mobility structures. In our proposed method we have distributed mobile nodes using Pareto distribution \& formulated various energy models using regression statistic.
\end{abstract}

\section{KEYWORDS}

Manet, Seed, Pareto, Regression

\section{INTRODUCTION}

A mobile communication has seen a rapid exponential growth. Mobile devices are preferred mode of communication for accessing the internet through Smartphones, Tablets etc. Mobile adhoc networks has no lasting network infrastructure. It establishes the transmission of new path in order to renovate the network route. There is the need for efficient management, optimization \& operation for improving the quality of signal, coverage $\&$ service. The node mobility and multiple hop characteristics of adhoc networks makes the fixed network routing protocol ineffectual to meet demands of adhoc network. Realization of different kind of mobile Ad hoc network routing protocols [1] has been done till now.An important aspect is the mathematical analysis \& modelling in which how much percent the capacity can be enhanced using probabilistic approaches $\&$ its role in routing the protocol for efficient energy management. 


\subsection{Related Work \& Novelty}

There are many challenges in wireless adhoc networks such as Routing, Mobility, Bandwidth constraint, Error prone \& shared channel, quick route reconfiguration [2]. Moreover, impact of distribution of mobile nodes using Pareto distribution on network performance for improving the capacity of adhoc network is a vital issue which has been discussed in this paper.

\subsubsection{Routing Protocols}

\section{Routing Protocol Proactive}

In proactive routing table, a node preserves routing information about other nodes in the network through one or more routing tables. This protocol requires a significant messaging overhead to maintain an ordered and updated routing table consuming more power, bandwidth and decreases the throughput.

\section{Reactive Routing Protocol -On Demand}

It is a on demand routing protocol. When idle, it does not maintain any routing Table. If a node wish to send a packet to another node then the protocol searches the path and tries to establish the connectivity for subsequent transmission $\&$ reception of packets.

\section{AODV}

AODV is mainly developed for Mobile Ad hoc networks, used in technologies like ZigBee. It is the algorithm which works on demand \& discovers route between nodes as per the requirement of the source node. This protocol uses route request messages (RREQ) which are swamped to the network for finding the path which is required by a source node [3].

\subsubsection{Energy Management}

\section{Energy Management}

Energy management [4] is the important process which utilizes the sources \& consumers of energy in a node or in the network as a whole for improving the lifetime of the network. Energy management will be useful for enhancing the battery life which is achieved by changing the node pattern using Pareto distribution; By using distributed scheduling schemes and handling the process and interface device for the minimization of power consumption.

\section{Transmission Power Management}

Design of hardware of Radio Frequency module should have minimum consumption of power in all three states of operations i.e. transmit, receive \& sleep. Going to the sleep mode when not transmitting or receiving can be done by additional hardware that can wake up on reception of control signal. The use of variable MAC protocol can lead to several advantage that includes energy saving at the nodes, increase in bandwidth reuse and reduction in interference. The network layer routing protocol can consider battery life \& relaying node of the intermediate nodes while selecting a path so that load can be balanced across the network. Performance analysis is also carried out using various Routing Protocols [5]. Routing protocol always tries to minimize energy consumption \& find out the most efficient approach [6]. Minimizing energy consumption using Meta Heuristic is elaborated in [7]. Various performance analysis of Routing protocols in wireless adhoc network for different mobility structures are covered in [8] \& [9]. 


\subsubsection{Probabilistic Approaches}

Random variables with different distributions will be created in Network Simulator. It has important role in traffic modelling and network simulation [10].

\section{Generator \& Seeds}

In insertion to its distribution, there will be other aspects too, to formulate random variables. The generation of random variables should be independent of each other. The generation of random variable is done using origin i.e. seed.

\section{Creating Random Variables}

We have created a new generator and assigned a seed value 2 using NS2 commands. When we actually create a random variable, we have to define its distribution type and its parameters. We create RVs with Pareto, Constant, Uniform and Hyper exponential distribution [11].

\section{Pareto Distribution}

A Pareto distribution RV, is constructed by specifying its expectation and its shape parameter.

$$
\mathrm{F}(\mathrm{x})=1-\left(1 / \mathrm{x}^{\mathrm{a}}\right) ; \quad \mathrm{a}>0 \quad \& 1 \leq \mathrm{x}<\infty
$$

Constant: A deteriorated random variable is the constant which equals to its values.

Uniform Distribution: It is defined across the smallest and largest point in its support.

\section{FINDINGS \& DISCUSSION}

For checking various computational parameters, no. of nodes \& its maximum number of replies, wireless adhoc network is simulated with various simulation parameters \& routing protocols as below. Energy model is also added in NS2 in order to find out various energy levels for different routing Protocol. Energy analysis of wireless nodes will help in deciding the network lifetime \& ensures energy saving capability of the node.

Table 1. Simulation Parameters

\begin{tabular}{|c|c|}
\hline Simulation Parameter & Type / Value \\
\hline Channel & wireless \\
\hline Propagation & Radio Propagation model \\
\hline Area & $1500 \times 1500$ \\
\hline No.of nodes & 20 \\
\hline Routing Protocol & AODV \\
\hline Initial energy & 5 \\
\hline TX power & 0.9 \\
\hline Rx-Power & 0.8 \\
\hline Idle Power & 0.0 \\
\hline
\end{tabular}




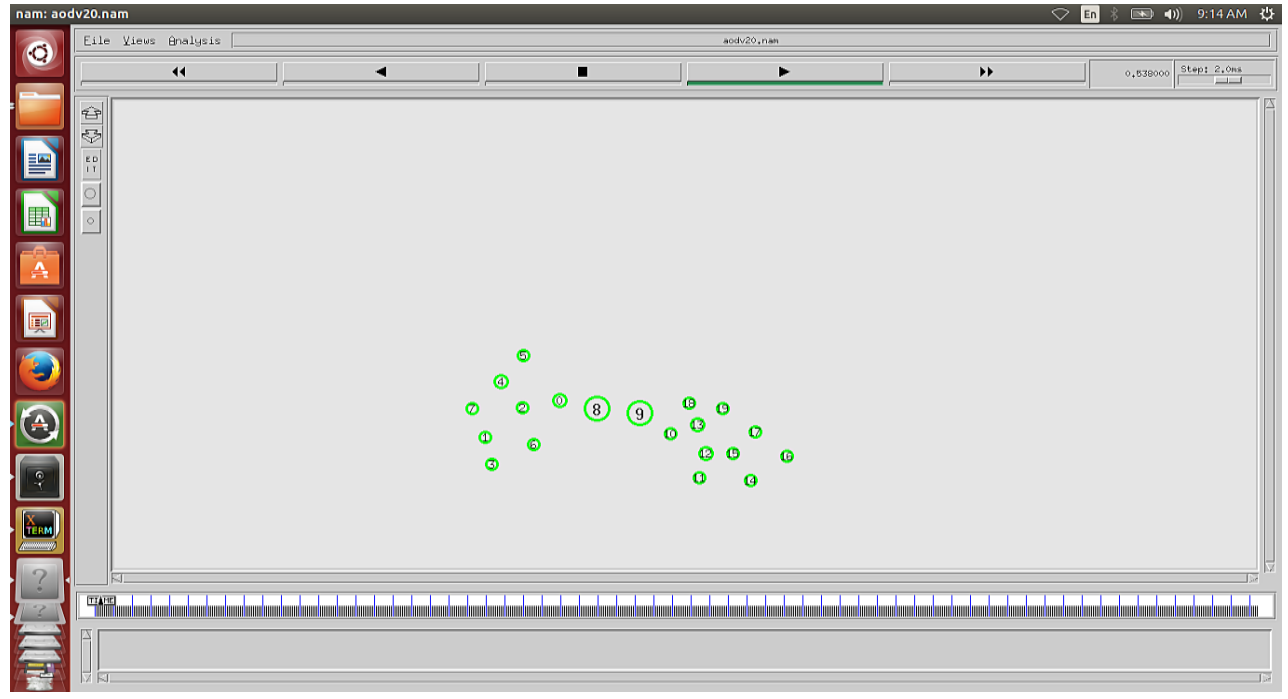

Fig. 1. NAM output for 20 mobile nodes using AODV Protocol

In figure 1, simulation results using NS2 are shown for wireless adhoc network using AODV routing protocol for 20 mobile nodes.

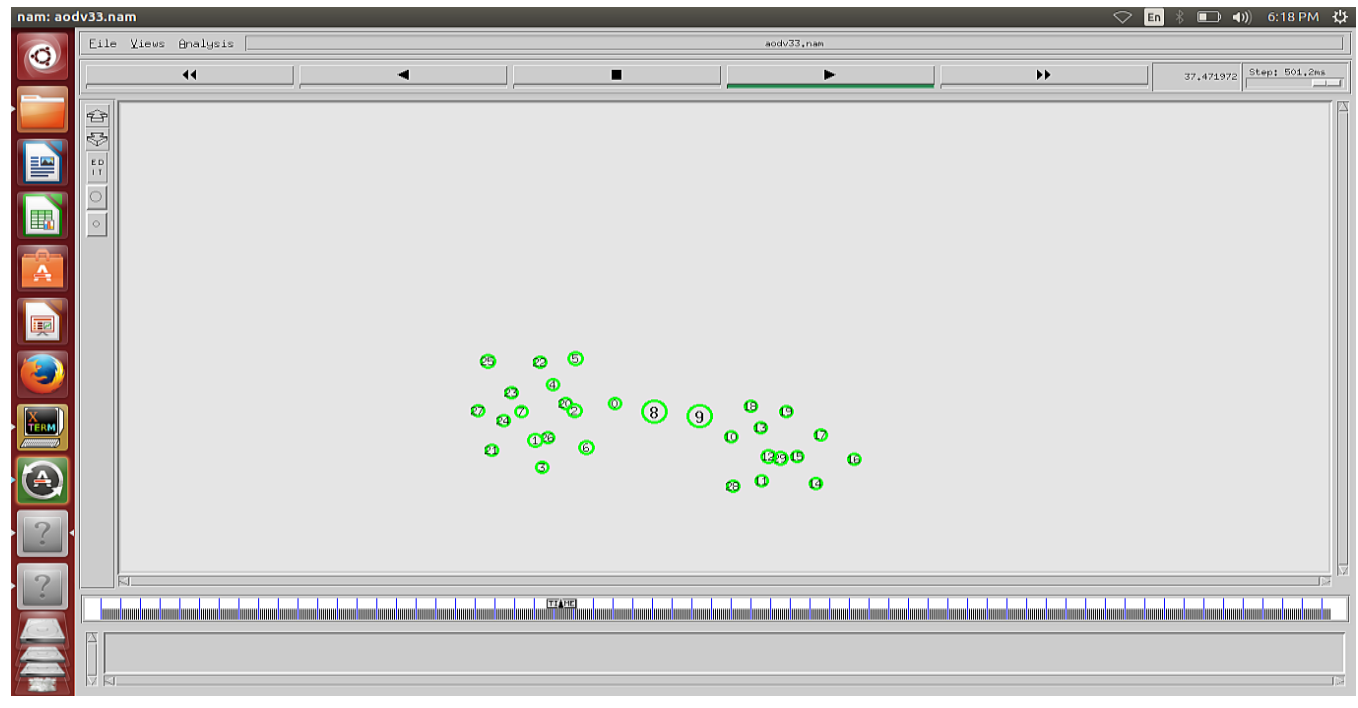

Fig.2. NAM output for 30 mobile nodes using AODV Protocol

In figure 2, simulation results are shown for wireless adhoc network using AODV routing protocol for 30 mobile nodes with the simulation parameters as indicated in Table-1.Table 2 lists values of computational parameters i.e. throughput, packet delivery ratio and residual energy after simulating various no.of mobile nodes. 
International Journal on Cybernetics \& Informatics (IJCI) Vol. 5, No. 1, February 2016

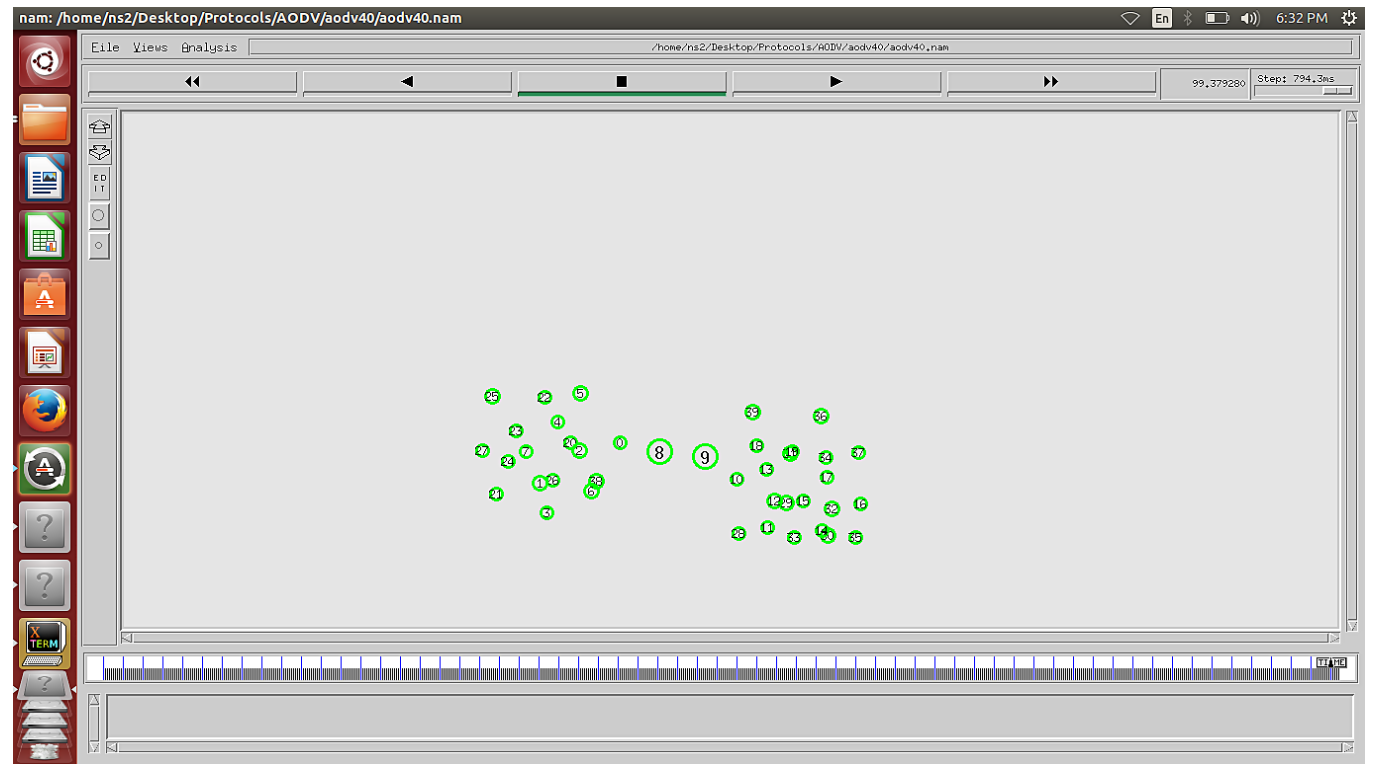

Fig.3. NAM output for 40 mobile nodes using AODV Protocol

Figure 3 shows NAM simulation for wireless adhoc network using AODV routing protocol for 40 mobile nodes.

From the table 2, it is clear that packet delivery ratio is better using DSDV protocol for low mobility network but energy level goes down after active communication is over.From the data of various computational parameters of above tables, we have run the regression and found following regression model for each table.

Table 2: Comparative analysis of various computational parameters i.e. Throughput, Packet delivery ratio and residual energy using DSDV Protocol.

\begin{tabular}{|c|c|c|c|}
\hline No. of nodes(n) & $\begin{array}{c}\text { Throughput } \\
\text { T(kbps) }\end{array}$ & $\begin{array}{c}\text { Packet delivery PDR } \\
(\%)\end{array}$ & $\begin{array}{c}\text { Residual Energy } \\
\text { in(Er) }(\mathrm{J})\end{array}$ \\
\hline 10 & 87.31 & 92.5 & 0.0017 \\
\hline 20 & 213.53 & 93.13 & 1.025 \\
\hline 30 & 408.89 & 86.8 & 1.005 \\
\hline 40 & 274.85 & 87.72 & 0.12 \\
\hline 50 & 289.9 & 82.0 & 0.52 \\
\hline
\end{tabular}

Table 3: Summary Output

\begin{tabular}{|c|c|c|}
\hline Sr.No & \multicolumn{2}{|c|}{ Regression statistic } \\
\hline 1 & Multiple R & 0.746143826 \\
\hline 2 & R Square & 0.556730609 \\
\hline 3 & Adjusted R Square & -0.773077562 \\
\hline 4 & Standard Error & 0.637854047 \\
\hline 5 & observation & 5 \\
\hline
\end{tabular}


International Journal on Cybernetics \& Informatics (IJCI) Vol. 5, No. 1, February 2016

Energy model computed using above regression is $\mathrm{Er}=-4.57-0.0046 * \mathrm{n}+0.0039 * \mathrm{~T}+0.048 * \mathrm{PDR}$

Table 4: Comparative analysis of various computational parameters i.e. throughput, packet delivery ratio and residual energy using AODV protocol

\begin{tabular}{|c|c|c|c|}
\hline $\begin{array}{c}\text { No. of } \\
\text { nodes(n) }\end{array}$ & $\begin{array}{c}\text { Throughput } \\
\text { T(kbps) }\end{array}$ & $\begin{array}{c}\text { Packet delivery } \\
\text { ratio (PDR) }(\%)\end{array}$ & $\begin{array}{c}\text { Residual energy } \\
\text { Er(J) }\end{array}$ \\
\hline 10 & 38.32 & 86.00 & 0.23 \\
\hline 20 & 83.66 & 90.61 & 4.27 \\
\hline 30 & 67.09 & 79.85 & 0.43 \\
\hline 40 & 23.96 & 61.36 & 3.93 \\
\hline 50 & 26.10 & 70.47 & 2.01 \\
\hline
\end{tabular}

From the table 4, it is clear that packet delivery ratio is better using AODV protocol for low mobility network as well as residual energy level is also better after active communication. Regression model derived for the data of table 4 is as follows:

Table 5: Summary Output

\begin{tabular}{|c|c|c|}
\hline Sr.No & \multicolumn{2}{|c|}{ Regression statistic } \\
\hline 1 & Multiple R & 1 \\
\hline 2 & R Square & 1 \\
\hline 3 & Adjusted R Square & 65535 \\
\hline 4 & Standard Error & 0 \\
\hline 5 & observation & 4 \\
\hline
\end{tabular}

Energy model computed using above regression is $\mathrm{Er}=5.82-0.55 * \mathrm{n}-0.42 * \mathrm{~T}+0.49 * \mathrm{PDR}$

Table 6: Comparative analysis of various computational parameters i.e. Throughput, Packet delivery ratio and residual energy using AOMDV Protocol

\begin{tabular}{|c|c|c|c|}
\hline $\begin{array}{c}\text { No. of } \\
\text { nodes } \\
(\mathrm{n})\end{array}$ & $\begin{array}{c}\text { Throughput } \\
\text { T(kbps) }\end{array}$ & $\begin{array}{c}\text { Packet Delivery } \\
\text { Ratio PDR }(\%)\end{array}$ & Residual energy Er(J) \\
\hline 10 & 132.47 & 78 & 0.21 \\
\hline 20 & 48.46 & 23.3 & 0.24 \\
\hline 30 & 68.38 & 23.2 & 1.76 \\
\hline 40 & 33.71 & 9 & 0.003 \\
\hline 50 & 82.42 & 23 & 0.79 \\
\hline
\end{tabular}

From the table 6, it is clear that packet delivery ratio \& residual energy level is not satisfactory using AOMDV protocol for low mobility network. Also the level of residual energy is not promising after active communication is over.

Regression model for the above table 6 is as follows: 
International Journal on Cybernetics \& Informatics (IJCI) Vol. 5, No. 1, February 2016

Table 7: Summary Output

\begin{tabular}{|c|c|c|}
\hline Sr.No & \multicolumn{2}{|c|}{ Regression statistic } \\
\hline 1 & Multiple R & 1 \\
\hline 2 & R Square & 1 \\
\hline 3 & Adjusted R Square & 65535 \\
\hline 4 & Standard Error & 0 \\
\hline 5 & observation & 4 \\
\hline
\end{tabular}

Energy model computed using above regression is

$$
\mathrm{Er}=5.82-0.55 * \mathrm{n}-0.42 * \mathrm{~T}+0.49 * \mathrm{PDR}
$$

In addition to above results, simulations are also carried out for wireless adhoc network using Pareto distribution for calculation of throughput, packet delivery ratio and residual energy \& values of these computational parameters are found to be same as if the same network simulated without Pareto distribution .The complete simulation results are shown below.

Table 8: Comparative analysis of various computational parameters i.e. Throughput, Packet delivery ratio and residual energy for Pareto distribution using AODV protocol

\begin{tabular}{|c|c|c|c|}
\hline No. of nodes(n) & $\begin{array}{c}\text { Throughput } \\
\text { T(kbps) }\end{array}$ & $\begin{array}{c}\text { Packet delivery } \\
\text { ratio PDR }(\%)\end{array}$ & $\begin{array}{c}\text { Residual } \\
\text { energy Er(J) }\end{array}$ \\
\hline 10 & 66.83 & 90.57 & 1.056 \\
\hline 20 & 83.66 & 94.0 & 1.77 \\
\hline 30 & 67.09 & 79.85 & 0.43 \\
\hline 40 & 23.96 & 61.36 & 3.93 \\
\hline 50 & 26.10 & 70.47 & 2.01 \\
\hline
\end{tabular}

Regression model for the above table 8 is as follows:

Table 9: Summary Output

\begin{tabular}{|c|c|c|}
\hline Sr.No & \multicolumn{2}{|c|}{ Regression statistic } \\
\hline 1 & Multiple R & 1 \\
\hline 2 & R Square & 1 \\
\hline 3 & Adjusted R Square & 65535 \\
\hline 4 & Standard Error & 0 \\
\hline 5 & observation & 4 \\
\hline
\end{tabular}

Energy model computed using above regression is

$$
\mathrm{Er}=11.28-0.28 * \mathrm{n}-0.2 * \mathrm{~T}+0.14 * \mathrm{PDR}
$$


International Journal on Cybernetics \& Informatics (IJCI) Vol. 5, No. 1, February 2016

Table 10: Comparative analysis of various computational parameters i.e. Throughput, Packet delivery ratio and residual energy for Pareto distribution using DSDV Protocol

\begin{tabular}{|c|c|c|c|}
\hline No. of nodes & $\begin{array}{c}\text { Throughput } \\
\text { (kbps) }\end{array}$ & $\begin{array}{c}\text { Packet Delivery } \\
\text { Ratio }(\%)\end{array}$ & $\begin{array}{c}\text { Residual Energy } \\
\operatorname{Er}(\mathbf{J})\end{array}$ \\
\hline 10 & 87.31 & 92.53 & 0.0017 \\
\hline 20 & 213.53 & 92.53 & 1.025 \\
\hline 30 & 408.89 & 86.80 & 1.005 \\
\hline 40 & 250.96 & 84.80 & 0.15 \\
\hline 50 & 289.90 & 82.00 & 0.52 \\
\hline
\end{tabular}

Table 11: Summary Output

\begin{tabular}{|c|c|c|}
\hline Sr.No & \multicolumn{2}{|c|}{ Regression statistic } \\
\hline 1 & Multiple R & 1 \\
\hline 2 & R Square & 1 \\
\hline 3 & Adjusted R Square & 65535 \\
\hline 4 & Standard Error & 0 \\
\hline 5 & observation & 4 \\
\hline
\end{tabular}

Energy model computed using above regression is $\mathrm{Er}=-59.19+0.17 * \mathrm{n}+0.009 * \mathrm{~T}+0.59 * \mathrm{PDR}$

Table 12: Comparative analysis of various computational parameters i.e. Throughput, Packet delivery ratio and residual energy for Pareto distribution using AOMDV protocol

\begin{tabular}{|c|c|c|c|}
\hline No. of nodes & $\begin{array}{c}\text { Throughput } \\
(\mathrm{kbps})\end{array}$ & $\begin{array}{c}\text { Packet Delivary } \\
\text { Ratio }(\%)\end{array}$ & $\begin{array}{c}\text { Residual Energy } \\
(\mathrm{J})\end{array}$ \\
\hline 10 & 132.47 & 72.78 & 0.21 \\
\hline 20 & 48.46 & 23 & 0.24 \\
\hline 30 & 68.38 & 23 & 1.76 \\
\hline 40 & 33.71 & 0.9 & 0.003 \\
\hline 50 & 82.42 & 23 & 0.79 \\
\hline
\end{tabular}

From the above table it is clear that packet delivery ratio is not promising using AOMDV protocol as well as residual energy is less after active communication.

Regression model for the above table 12 is as follows:

Table 13: Summary Output

\begin{tabular}{|c|c|c|}
\hline Sr.No & \multicolumn{2}{|c|}{ Regression statistic } \\
\hline 1 & Multiple R & 1 \\
\hline 2 & R Square & 1 \\
\hline 3 & Adjusted R Square & 65535 \\
\hline 4 & Standard Error & 0 \\
\hline 5 & observation & 4 \\
\hline
\end{tabular}

Energy model computed using above regression is $\mathrm{Er}=1.28-0.16^{*} \mathrm{n}+0.16^{*} \mathrm{~T}-0.24 * \mathrm{PDR}$ 


\section{CONCLUSION}

The research work carried out debriefs new dimensions in the analysis of computational parameters of wireless adhoc network with \& without application of Pareto distribution for changing node placement in wireless adhoc network. Energy of a node gradually reduces along with time. It is basically a proactive routing table in which each and every node has to maintain its own routing table to forward packet to its destination. But at the end of a simulation, energy of the node varies due to addition of new node in a path because MANET do not have fixed infrastructure. Residual energy of a node is retained more with the node even after active communication with AODV protocol as compared to DSDV for low mobility network scenario. The proposed method demonstrates the simulation of wireless adhoc network up to 50 mobile nodes using Pareto distribution \& its comparison is carried out for its computational parameters i.e. throughput, packet delivery ratio \& residual energy with and without applying pareto distribution . It is concluded that, even if we simulate the network by changing the node placement using Pareto distribution, it does not affect the computational parameters of the network for low mobility network and linear models for each results shows that $\mathrm{R}^{2}>0.5$ which indicates that independent variables explains good amount of variation for predicting future values of energy for given input.

\section{REFERENCE}

[1] Zulfiqar Ali, Waseem Shahzad, "Analysis of Routing Protocols in Adhoc and Sensor Wireless Networks based on swarm intelligence,"International Journal of Networks and Communications, ISSN: 2168- 4936.

[2] Sofia Hamad, Hadi Noureddine and hamed AL Raeshidy, "Link Stability and Energy Aware for efficient Routing in Mobile Adhoc Network," $14^{\text {th }}$ international symposium on wireless network, 2011.

[3] YANG Yin-jun, "Improvement and Analysis of Multipath Routing Protocol AOMDV based on CMMBCR," 2011 IEEE

[4] Md. Nafees Rahman, M. A. Matin, "Efficient Algorithm for Prolonging Network Lifetime of Wireless Sensor Networks," pp 561- 568 Volumes 16, Number 6, December 2011

[5] S. Mohapatra, P.Kanungo, "Performance analysis of AODV, DSR, OLSR and DSDV routing protocol using NS2 Simulator", international Conference on Communication Technology and System Design 2011, Elsevier, March 13, 2012.

[6] A Review on Energy Efficient Approaches for AODV Protocol, "International Journal of Engineering,sciences and researchTechnology, ISSN: 2277- 9655, May 2013.

[7] Ibukunola.A.Modupe, Oludayo.O.Olugbara, Minimizing energy consumption in Wireless Adhoc Networks with Meta Heuristics," the fourth International conference in Wireless Adhoc Networks with Meta heuristics, Procedia Computer Science 19 (2013), 106- 115

[8] Geethu Mohandas, Dr.Salaja Silas \& Shini Sam, "Servey on Routing Protocols on Mobile Adhoc Networks", Automation, Computing, "Communication, Control and Compressed Sensing, 2013 Conference.

[9] B. Nancharaiah, B. Chandra Moan, "The performance of hybrid Routing Intelligent algorithm in mobile Adhoc Networks," Elsevier, May 2014.

[10] Hui zhang Sheng Chen, ̈̈ universal Approach for coverage probability \& Throughput analysis for cellular Networks", IEEE Transactions on vehicular vehicular Technolgy, Vol 64, No.9, Sept 2015.

[11] David Gonzalez and Jyri Hamalainer,'Topology and irreguarityin cellular Networks"2015 IEEE Wireless communication and Network Conference(WNNC):-Track 3: Mobile \& Wireless networks 


\section{AUTHORS}

Mr. Suresh Kurumbanshi is B.E. and M.Tech in Electronics Engineering from RTM Nagpur University, Nagpur. He is Pursuing Ph.D. in Electronics Engineering from Department of Electronics \& Telecommunication Engineering, Yeshwantrao Chavan College of Engineering, Nagpur. He has an industrial experience in Finolex Cables ltd, Pune \& was working as a Sr. Lecturer in Electronics Department of G.H.Raisoni college of Engineering Nagpur. Later on he was handling responsibility of Head of Electronics Engineering Department at Rajiv Gandhi College of Engineering, Nagpur. Recently he

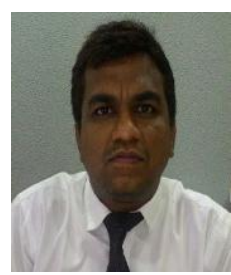
was Head of Applied Sciences \& Humanities Department in NMIMS University, Mumbai, Shirpur off Campus. He is currently working as Assistant Professor in the Department of Electronics \& Telecommunication Engineering and In-charge of ISTE Chapter in MPSTME, NMIMS University, Shirpur Campus. His research area includes Adhoc Network, Mobile communication using stratospheric platforms.

Dr. Shubhangi Vikas Rathkanthiwar is presently working as Professor and Head of Department of Electronics Engineering, Yeshwantrao Chavan College of Engineering, Nagpur, India and as Deputy Director, International relations office, Meghe Group of Institutions, India. Her area of expertise is Wireless Communications and Soft Computing. She has 72 research papers in her credit. Her book 'An intelligent Wireless LAN system: Performance evaluation in fading multipath environment' is published in Germany. She is recognized reviewer of Journal of Applied Soft Computing, Elsevier,

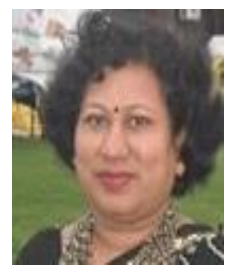
IEEE transactions on Vehicular Technology and IEEE transactions on Industrial Electronics. She is reviewer and Technical program committee member of several IEEE conferences. She is editorial member of several International Journals. She has filed two patent applications and one of her patent is published by Government of India. She is recipient of Best research paper award, Best Teacher award and 'Shikshak Ratna award'. 